\title{
METHODOLOGY
}

\section{Provocation by eucapnic voluntary hyperpnoea to identify exercise induced bronchoconstriction}

\author{
S D Anderson, G J Argyros, H Magnussen, K Holzer
}

\begin{abstract}
The International Olympic Committee Medical Commission (IOC-MC) requires notification for use of a $\beta_{2}$ agonist at the Winter Olympic Games in Salt Lake City. This notification will be required seven days before the event and must be accompanied by objective evidence that justifies the need to use one. The IOC-MC has expressed the viewpoint that, at present, eucapnic voluntary hyperpnoea (EVH) is the optimal laboratory challenge to confirm that an athlete has exercise induced bronchoconstriction (EIB). The EVH test recommended was specifically designed to identify EIB. EVH has been performed in thousands of subjects in both the laboratory and the field. The test requires the subject to hyperventilate dry air containing $5 \%$ carbon dioxide at room temperature for six minutes at a target ventilation of 30 times the subject's forced expiratory volume in one second $\left(\mathrm{FEV}_{1}\right)$. The test conditions can be modified to simulate the conditions that give the athlete their symptoms with exercise. A reduction in $\mathrm{FEV}_{1}$ of $10 \%$ or more of the value before the test is considered positive.

(Br F Sports Med 2001;35:344-347)
\end{abstract}

Keywords: hyperpnoea; bronchial provocation; exercise

At a recent meeting of the International Olympic Committee Medical Commission in Lausanne it was recommended that notification for the use of a $\beta_{2}$ agonist before an event would require clinical and laboratory (including respiratory function tests) evidence to justify the need for such medication. While acceptable evidence could be submitted in many forms, an abnormal airway response to a bronchial provocation test with eucapnic voluntary hyperpnoea (EVH) was identified as confirmation that an athlete has exercise induced bronchoconstriction (EIB). EIB is a well recognised medical indication for the prophylactic use of $\beta_{2}$ agonists, so that its documentation would appear to justify the need for prophylaxis with a $\beta_{2}$ agonist before exercise.

The need for objective testing to identify EIB is supported by the knowledge that, in athletes, respiratory symptoms do not predict $\mathrm{EIB}^{12}$ and cannot be used to justify the need for medication to prevent it. There are limitations in using laboratory based exercise tests to identify EIB in elite athletes, ${ }^{3}$ and there is a high prevalence of it in winter athletes. ${ }^{4}$ The EVH test is suggested as an alternative to exercise as a laboratory based test to identify EIB.

\section{Reasons for recommendation}

Bronchial provocation with EVH was recommended for the following reasons: (a) EVH is a potent challenge test for provoking bronchoconstriction in clinically recognised asthmatics responsive to exercise ${ }^{5}$; (b) the symptoms provoked by EVH such as cough, dyspnoea, and wheeze are the same as those reported with exercise; (c) EVH testing requires less expensive equipment and fewer personnel than exercise testing; (d) EVH can induce ventilation rates equivalent to or higher than most forms of exercise, and the ventilation rate achieved can usually be sustained over six minutes; (e) the maximum airway response to EVH is similar to that achieved by exercise, and occurs within the first 10 minutes of cessation of the hyperpnoea; $(f)$ as with exercise, ${ }^{6} \beta_{2}$ agonists are effective in inhibiting the airway narrowing to $\mathrm{EVH}^{7} ;(g)$ as with exercise, a variety of inflammatory mediators, including histamine, prostaglandins, ${ }^{8}$ and leukotrienes, ${ }^{9}$ are likely to be involved in the response to EVH; $(h) \mathrm{EVH}$ has a very high specificity for identifying persons with clinically recognised asthma ${ }^{10} ;(i)$ publications are readily available on the standardisation, application, and interpretation of EVH testing; ( $)$ $\mathrm{EVH}$ has been used safely in many thousands of subjects including adults and children ${ }^{11-13}$; (k) EVH has been used with some success to identify EIB in cold weather athletes ${ }^{14}$; $(l) \mathrm{EVH}$ testing has the potential to be tailored to simulate the respiratory demands of exercise and the inspired air conditions that provoke symptoms in the athlete.

\section{Mechanism of airway narrowing to hyperpnoea}

The mechanisms proposed to explain why the airways narrow in response to intense exercise or eucapnic hyperpnoea of dry air are also likely to account for other symptoms in athletes performing exercise, particularly in the cold. ${ }^{15}$ The response to breathing dry air is thought to cause the airways to narrow by osmotic and thermal consequences of evaporative water loss 
from the airway surface in response to humidifying the inspired air. ${ }^{16}$ These stimuli have potential to cause cough ${ }^{17}$ and mucus production $^{18}$ in the absence of airway narrowing; this may explain why these symptoms do not necessarily predict EIB. ${ }^{1}$ When airway inflammation is present, a hyperosmolar environment can result in the release of mediators that induce contraction of bronchial smooth muscle and airway narrowing. ${ }^{15}$ Airway cooling is also a consequence of respiratory water loss, particularly air of subfreezing temperatures inspired during exercise. It has been proposed that the airway narrowing caused by cooling results from a reactive hyperaemia of the bronchial vasculature and airway oedema after vasoconstriction. ${ }^{19}$ These vascular events may amplify the narrowing of the airway caused by the normal contraction of the bronchial smooth muscle or the presence of mucus. ${ }^{15}$

\section{The EVH test}

The EVH test recommended and described below was originally developed, standardised, and validated by members of the US army at the Walter Reed Hospital in Washington DC. ${ }^{10-24}$ It was specifically developed as a surrogate for an exercise test to identify EIB. In brief, the test requires the subject to hyperventilate voluntarily a dry gas consisting of air at room temperature. This gas contains about $5 \%$ carbon dioxide, a concentration that will maintain carbon dioxide levels in the arterial blood within the range documented during exercise. The target ventilation rate is $30 \times$ forced expiratory volume in one second $\left(\mathrm{FEV}_{1}\right)$, equivalent to $85 \%$ the maximum voluntary ventilation (MVV), and the duration of the test is six minutes. Although this particular protocol for EVH is recommended, it should be noted that the potential exists to change the inspired air temperature, ventilation rate, and duration of the test to simulate the conditions under which the athlete is provoked.

The EVH test described below is intended to identify the potential for an athlete to have EIB. EVH can also be used to show efficacy of a $\beta_{2}$ agonist or mast cell stabiliser, such as sodium cromoglycate or nedocromil sodium, in inhibiting or preventing the induced reduction in lung function. This protocol is relevant for testing of athletes with an $\mathrm{FEV}_{1}$ value greater than $75 \%$ of predicted normal for sex, age, and height. For subjects with lower lung function or those known to have moderate to severe asthma, we recommend the progressive protocol for EVH described by Brannan et al. ${ }^{25}$

CONDITIONS BEFORE THE TEST

To maximise a significant airway response to $\mathrm{EVH}$, the subject should have had no short acting bronchodilators, sodium cromoglycate, nedocromil sodium, or ipratropium bromide, for eight hours and no long acting or sustained release bronchodilators or antihistamines for 48 hours. The minimum washout period for a leukotriene antagonist has not been firmly established, but we would suggest four days. No caffeine should be taken on the morning of the study (some laboratories request 24 hours without beverages or food containing caffeine). No vigorous exercise should be undertaken for at least four hours before attendance at the laboratory and preferably none on the day of testing because of the possibility of developing refractoriness. $^{720}$ Chronic treatment with inhaled steroids reduces the response to $\mathrm{EVH},{ }^{26}$ and we suggest that inhaled steroids are not used on the day of the test to optimise the chance of a positive response. In the event of a negative test in an asthmatic subject well controlled on inhaled steroids, other objective evidence such as a significant response to a bronchodilator may need to be submitted to justify the need to premedicate with a $\beta_{2}$ agonist.

\section{CONDITION OF INSPIRED AIR}

The inspired air is dry and contains $21 \%$ oxygen, $4.9-5.1 \%$ carbon dioxide, with the balance nitrogen. The simplest and safest way to deliver the mixture is from a gas cylinder containing the inspired concentrations of the gases. It is possible to add carbon dioxide to the inspired air, but this requires careful monitoring of the end tidal carbon dioxide to ensure eucapnoea. Unless the response under these conditions is negative, it would not appear necessary to have a longer duration of hyperpnoea than six minutes or to condition the inspired air to subfreezing conditions. In asthmatics, the response to four minutes of hyperpnoea with cold air is equivalent to eight minutes of hyperpnoea with air at room temperature. ${ }^{27}$ If a cool inspirate is required, commercially available heat exchangers can be used, such as the Air-jet PTS System (Stoneridge, New York, New York, USA) or Jaeger RES (Erich Jaeger $\mathrm{GmbH}$, Wurzberg, Germany). Another simpler device (Turboaire Challenge; Equilibrated BioSystems Inc, Melville, New York, USA) is also commercially available, but its use considerably reduces the number of tests that can be performed per cylinder. It is also possible to cool the inspired air by passing the air mixture either through or over a cooling coil immersed in substances such as ethylene glycol, a mixture of ice and acetone, isopropyl alcohol, freon, or methanol cooled to $-35^{\circ} \mathrm{C}$.

MEASUREMENT OF THE AIRWAY RESPONSE

The $\mathrm{FEV}_{1}$ is measured three times before the challenge, and the highest measurement used to calculate the airway response. The three values should agree to within $200 \mathrm{ml}$, and they should be performed in accordance with American Thoracic Society criteria. ${ }^{28}$ The $\mathrm{FEV}_{1}$ is measured in duplicate immediately after the challenge and at five, 10, 15, and 20 minutes after EVH. An additional measurement can be made at three minutes.

\section{THE TEST}

The single stage protocol requires hyperventilation for six minutes at a target ventilation rate equivalent to $30 \times \mathrm{FEV}_{1}$ (litres corrected to body temperature, pressure, and fully saturated (BTPS)) measured immediately before the test. This is only a target ventilation rate. Most elite athletes should easily achieve $25 \times \mathrm{FEV}_{1}$, 


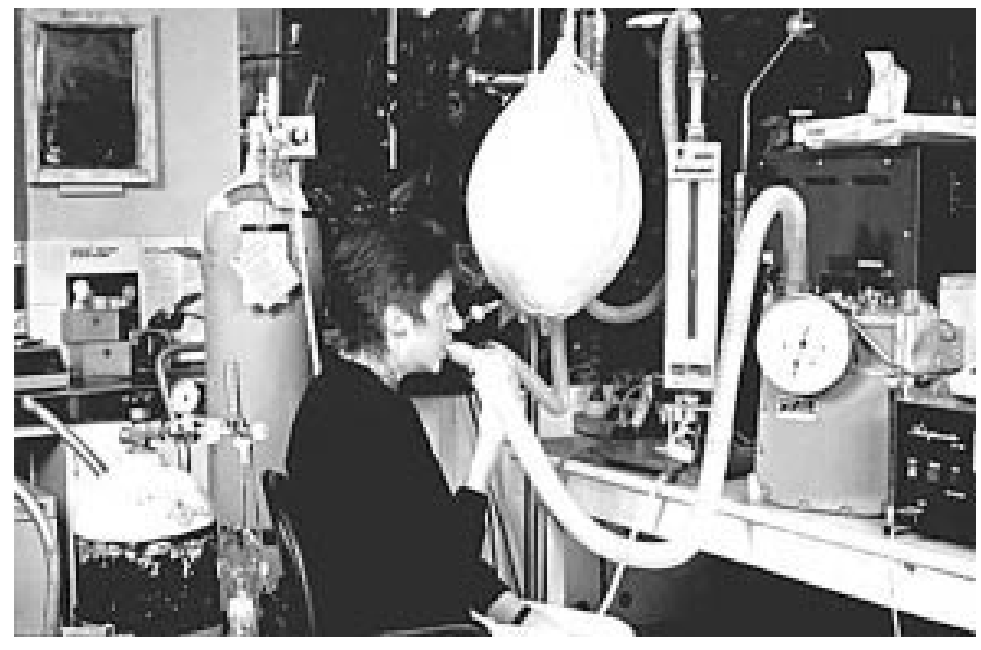

Figure 1 A subject is shown undergoing a eucapnic voluntary hyperpnoea challenge with the equipment described in the text. For an elite athlete, the balloon used would have to be the larger $300 \mathrm{~g}$ size. Note the presence of the oxygen and bronchodilator close by.

and most asthmatics need only breathe at $21 \times$ $\mathrm{FEV}_{1}$ to have an abnormal response. Although the subject could inhale directly from a demand valve, these valves provide a significant inspiratory resistance at high flow rates. For this reason a meteorological balloon (120 litre capacity) is recommended to act as reservoir. The balloon is filled initially with 90 litres and then continuously filled at a rate close to the target ventilation rate during the challenge. The rate is checked by placing a rotameter between the cylinder and the balloon. The use of a rotameter is not essential if the expired ventilation is being measured continuously (figs 1 and 2). The subject breaths through a two way valve, and, when the hyperpnoea begins, is encouraged to keep the volume of the balloon constant while it is being filled at the target ventilation rate. The balloon should not be overfilled, as the distending pressure will cause the expiratory valve to open and hence the expired ventilation to be overestimated. A metronome can be used to guide the frequency of respiration in accordance with that attained during exercise. Expired ventilation can simply be measured either as the cumulative amount at the end of the test, corrected for time, or after each minute. A gas meter or other suitable device for measuring ventilation can be used. The volume is corrected to BTPS. Figure 2 gives an example of the equipment used for the EVH challenge. Most laboratories could readily adapt their exercise equipment to achieve a similar circuit. The minimal equipment needed for $\mathrm{EVH}$ is the gas mixture, a means of delivering it, and a spirometer to measure $\mathrm{FEV}_{1}$. A measurement of ventilation, although highly recommended, is not needed to establish the existence of a response. However, a measure of the ventilation is needed to assess the stimulus to induce that response and the severity of the response.

\section{Expressing and interpreting the severity of the airway response}

Airway narrowing in response to $\mathrm{EVH}$ is assessed by measuring changes in $\mathrm{FEV}_{1}$. The percentage fall in $\mathrm{FEV}_{1}$ is calculated as follows:

$100 \times\left(\mathrm{FEV}_{1}\right.$ (before the test) - lowest value for $\mathrm{FEV}_{1}$ measured in the 20 minutes after the test $) \div \mathrm{FEV}_{1}$ before the test.

A reduction in $\mathrm{FEV}_{1}$ of $11.3 \%$ or more is outside the $95 \%$ confidence limit for healthy subjects when the single six minute protocol is used with air at room temperature. ${ }^{22}$ Hurwitz et $a l^{22}$ concluded that in a "proper clinical setting subjects whose $\mathrm{FEV}_{1}$ declines by $10 \%$ or more

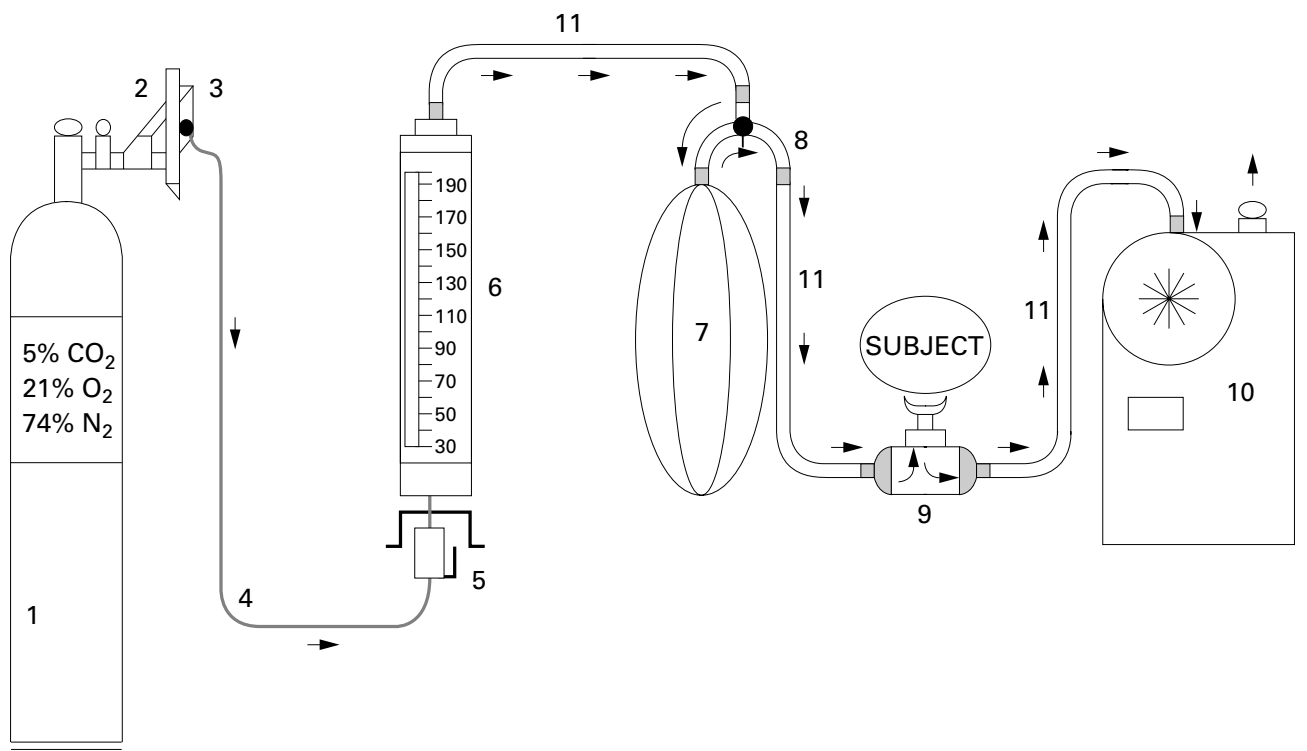

Figure 2 Equipment for eucapnic voluntary hyperpnoea test. 1, Compressed gas mixture; 2, regulator; 3, demand resuscitator, 30-150 litres/min; 4, high pressure tubing; 5, demand valve; 6, rotameter, 30 to >200 litres/min (Fisher-Rosemount, Brooks Instruments, Hatfield, Pennsylvania, USA); 7, meteorological balloon, 100-300 g (for example, Balloon Meteorological Day Flight, $300 \mathrm{~g}$ MFG No $100 \mathrm{MRL}$; Kaysam Corporation of America, Paterson, New fersey, USA) or a Douglas Bag of 150 litres capacity (Collins, Braintree, Massachusetts, USA); 8, metal connector with tap that allows gas to simultaneously enter and leave the balloon (for example, Morgan PKM 90750105 000); 9, low resistance, low dead space volume (for example, Hans Rudolph valve No 1400 for children or 2700 for adults); 10, gas meter (for example, American Dry Test Meters; American Meter Company, Horsham, Pennsylvania, USA) accurate to 1 litre or any other device; 11, hoses, minimum diameter 1.25 inches. Arrows indicate direction of flow of gas. 
at 5 or 10 min after EVH should be diagnosed as having asthma". This value is in accord with the findings of others in thousands of healthy subjects subjected to cold air challenge. ${ }^{12} 132930$ Further, a value of $10 \%$ would be in keeping with a diagnosis of EIB.

\section{Expressing and interpreting the stimulus causing the response}

The stimulus is reported as the average ventilation rate, in litres BTPS per minute over the period of the test, expressed as a percentage of the predicted MVV. MVV is defined as a multiple of $35 \times$ measured $\mathrm{FEV}_{1}$. Expressing the provoking stimulus as a percentage of the predicted MVV gives a guide to the intensity of exercise that would be required to provoke the reduction in lung function. The maximum ventilation achievable during exercise in a healthy person rarely exceeds $60 \%$ of the MVV, and in an elite athlete it would rarely exceed $90 \%$ of their MVV.

Bronchial responsiveness to a provoking stimulus is often referred to and interpreted as mild, moderate, or severe. The response is mild if the fall in $\mathrm{FEV}_{1}$ is between 10 and $19.9 \%$ when the ventilation is $60 \% \mathrm{MVV}$ or more and moderate when the fall is between $20 \%$ and $29.9 \%$. The response is severe when the fall in $\mathrm{FEV}_{1}$ is $30 \%$ or more at any level of ventilation or if a fall greater than $10 \%$ occurs at a ventilation rate less than $30 \% \mathrm{MVV}$.

\section{Safety}

Thousands of EVH tests have been performed without serious unwanted side effects. ${ }^{11-13}$ However, EVH has the potential to provoke severe bronchoconstriction, and for this reason a bronchodilator and supplemental oxygen should be available at the site of testing. It is recommended that, as with the performance of any other bronchial provocation tests, medical personnel and resuscitative equipment be readily available.

The authors would like to thank Ken Rundell PhD, FACSM of the United States Olympic Training Center, Lake Placid, New York, USA for his helpful comments.

1 Rundell KW, Im J, Mayers LB, et al. Self-reported symptoms and exercise induced asthma in the elite athlete. Med $\mathrm{Sc}$ Sports Exer 2001;33:208-13.

2 Anderson SD, Camps J, Perry CP, et al. Prevalence of exercise induced bronchoconstriction (EIB) in young athletes identified by eucapnic voluntary hyperpnoea $(\mathrm{EVH})$ [abstract]. Respirology 2001;6:A10

3 Rundell KW, Wilber RL, Szmedra L, et al. Exercise induced asthma screening of elite athletes: field vs laboratory exercise challenge. Med Sci Sports Exerc 2000;32:309-16.

4 Wilber RL, Rundell L, Szmedra L, et al. Incidence of exercise induced bronchospasm in Olympic Winter Sport athletes. Med Sci Sports Exer 2000; in press.

5 Deal EC, McFadden ER, Ingram RH, et al. Hyperpnoea and heat flux: initial reaction sequence in exercise induced asthma. $\mathcal{F}$ Appl Physiol 1979;46:476-83.
6 Anderson SD, Lambert S, Brannan JD, et al. Laboratory protocol for exercise asthma to evaluate salbutamol given by two devices. Med Sci Sports Exer 2001;33:893-900.

7 Nowak D, Jorres R, Rabe KF, et al. Salmeterol protects against hyperventilation induced bronchoconstriction over 12 hours. Eur f Clin Pharmacol 1992;43:591-5.

8 Finnerty JP, Harvey A, Holgate ST. The relative contributions of histamine and prostanoids to bronchoconstriction provoked by isocapnic hyperventilation in asthma. Eur Respir f 1992;5:323-30.

9 Israel E, Dermarkarian R, Rosenberg M, et al. The effects of a 5-lipoxygenase inhibitor on asthma induced by cold, dry air. N Engl f Med 1990;323:1740-4.

10 Eliasson AH, Phillips YY, Rajagopal KR. Sensitivity and specificity of bronchial provocation testing. An evaluation of four techniques in exercise induced bronchospasm. Chest 1992;102:347-55.

11 Deal EC, McFadden ER, Ingram RH, et al. Airway responsiveness to cold air and hyperpnoea in normal subjects and in those with hay fever and asthma. Am Rev Respir Dis $1980 ; 121: 621-8$

12 Nicolai T, Mutius EV, Reitmeir P, et al. Reactivity to cold-air hyperventilation in normal and in asthmatic children in a survey of 5,697 schoolchildren in southern Bavaria. Am Rev Respir Dis 1993;147:565-72.

13 Weiss ST, Tager IB, Weiss JW, et al. Airways responsiveness in a population sample of adults and children. Am Rev Respir Dis 1984;129:898-902.

14 Mannix ET, Manfredi F, Farber MO. A comparison of two challenge tests for identifying exercise induced bronchospasm in figure skaters. Chest 1999;115:649-53.

15 Anderson SD, Holzer K. Exercise induced asthma: is it the right diagnosis in elite athletes? F Allergy Clin Immunol 2000;106:419-28.

16 Anderson SD, Daviskas E. The mechanism of exercise induced asthma is . . F A Allergy Clin Immunol 2000;106: 453-9.

17 Banner AS, Green J, O'Connor M. Relation of respiratory water loss to coughing after exercise. $N$ Engl $f$ Med 1984;311:883-6.

18 Dwyer TM, Farley JM. Mucus glycoconjugate secretion in cool and hypertonic solutions. Am $\mathcal{f}$ Physiol 1997;272: L1121-5.

19 McFadden ER, Lenner KA, Strohl KP. Postexertional airway rewarming and thermally induced asthma. $\mathcal{F}$ Clin Invest 1986;78:18-25.

20 Argyros GJ, Roach JM, Hurwitz KM, et al. The refractory period after eucapnic voluntary hyperventilation challenge and its effect on challenge technique. Chest 1995;108:41924.

21 Argyros GJ, Roach JM, Hurwitz KM, et al. Eucapnic voluntary hyperventilation as a bronchoprovocation technique. tary hyperventilation as a bronchoprovocation technique.
Development of a standardized dosing schedule in Development of a standardized

22 Hurwitz KM, Argyros GJ, Roach JM, et al. Interpretation of eucapnic voluntary hyperventilation in the diagnosis of asthma. Chest 1995;108:1240-5.

23 Phillips YY, Jaeger JJ, Laube BL, et al. Eucapnic voluntary hyperventilation of compressed gas mixture. A simple system for bronchial challenge by respiratory heat loss. Am Rev Respir Dis 1985;131:31-5.

24 Roach JM, Hurwitz KM, Argyros GJ, et al. Eucapnic voluntary hyperventilation as a bronchoprovocation technique. Comparison with methacholine inhalation in asthmatics. Chest 1994;105:667-72.

25 Brannan JD, Anderson SD, Koskela H, et al. Responsiveness to mannitol in asthmatic subjects with exercise and hyperventilation induced asthma. Am f Respir Crit Care Med 1998;158:1120-6.

26 Vathenen AS, Knox AJ, Wisniewski A, et al. Effect of inhaled budesonide on bronchial reactivity to histamine, exercise, and eucapnic dry air hyperventilation in patients with asthma. Thorax 1991;46:811-16.

$27 \mathrm{McF}$ adden ER, Nelson JA, Skowronski ME, et al. Thermally induced asthma and airway drying. Am $\mathcal{F}$ Respir Crit Care Med 1999;160:221-6.

28 American Thoracic Society. Standardization of spirometry: 1994 update. Am $\mathcal{F}$ Respir Crit Care Med 1995;152:110736.

29 Assoufi BK, Dally MB, Newman-Taylor AJ, et al. Cold air test: a simplified standard method for airway reactivity. Bull Eur Physiopathol Respir 1986;22:349-57.

30 Zach M, Polgar G, Kump H, et al. Cold air challenge of airway hyperreactivity in children: practical application and theoretical aspects. Pediatr Res 1984;18:469-78.

\section{Take home message}

Voluntary hyperpnoea with dry air is a standardised bronchial provocation test to identify athletes with exercise induced bronchoconstriction or exercise induced asthma in a laboratory environment. 